\title{
Novel drug delivery systems of Chinese medicine for the treatment of inflammatory bowel disease
}

\author{
Caifang Gao ${ }^{1 \dagger}$, Lijuan Liu ${ }^{1,2,3 \dagger}$, Yangyang Zhou ${ }^{1}$, Zhaoxiang Bian ${ }^{4}$, Shengpeng Wang ${ }^{1,5^{*}}$ (D) and Yitao Wang ${ }^{{ }^{*}}$
}

\begin{abstract}
Inflammatory bowel disease (IBD) is an idiopathic intestinal inflammatory disease that comprises ulcerative colitis (UC) and Crohn's disease (CD). IBD involves the ileum, rectum, and colon, and common clinical manifestations of IBD are diarrhea, abdominal pain, and even bloody stools. Currently, non-steroidal anti-inflammatory drugs, glucocorticoids, and immunosuppressive agents are used for the treatment of IBD, while their clinical application is severely limited due to unwanted side effects. Chinese medicine (CM) is appealing more and more attention and investigation for the treatment of IBD owing to the potent anti-inflammation pharmacological efficacy and high acceptance by patients. In recent years, novel drug delivery systems are introduced apace to encapsulate CM and many CM-derived active constituents in order to improve solubility, stability and targeting ability. In this review, advanced drug delivery systems developed in the past and present to deliver CM for the treatment of IBD are summarized and future directions are discussed.
\end{abstract}

Keywords: Inflammatory bowel disease, Chinese medicine, Drug delivery system, Ulcerative colitis

\section{Background}

Inflammatory bowel disease (IBD) is a chronic and multifactorial inflammatory disorder of the intestinal tract, associating with an immunological imbalance of the intestinal mucosa [1]. IBD is commonly known to be classified into two major subtypes, namely ulcerative colitis (UC) and Crohn's disease (CD). UC is a continuous inflammation of the colonic mucosa, while $\mathrm{CD}$ is a non-continuous whole-layer inflammation and can affect any region of the whole gastrointestinal tract (GIT) from the mouth to the anus $[2,3]$. Typically, clinical manifestations of IBD are characterized as abdominal pain, diarrhea, weight loss, and even bloody stools. Moreover, a relentless climb in incidence has been observed among the younger in recent decades [4]. With the development

\footnotetext{
*Correspondence: swang@um.edu.mo; ytwang@umac.mo; ytwang@um.edu.mo

${ }^{\dagger}$ Caifang Gao and Lijuan Liu equally contributed to this work

1 State Key Laboratory of Quality Research in Chinese Medicine, Institute of Chinese Medical Sciences, University of Macau, Avenida da Universidade, Taipa, Macao, SAR, China

Full list of author information is available at the end of the article
}

and progression of IBD, various complications and other conditions occasionally develop, such as stenosis, fistula and colitis-associated cancer. Given its early onset, chronic nature and the need for treatment till the end of life, the cost of medical treatment for IBD would be enormous and impose a significant economic burden on IBD patients.

Historically, patients with IBD were treated with non-biological therapies, containing 5-aminosalicylic acid (5-ASA), antibiotics, and in some cases, steroids. Among these conventional therapies, corticosteroids are considered to be the most effective therapies, providing symptomatic improvement for patients with IBD [5]. However, with the emerging side effect and steroiddependent remission by non-biological treatment, new biological therapies have been clinically developed, such as anti-tumor necrosis factor (TNF) agents (infliximab, adalimumab, and certolizumab), anti-adhesion molecules (vedolizumab), some blockage of downstream signaling (tofacitinib), proinflammatory cytokines (ustekinumab), and others agents like ozanimod [6-10]. Although these new biological therapies have been reported to be well 
tolerated, their effectiveness in treating all patients is moderate and the safety problems associated with risks of GIT ulcers, bleeding and perforation, metabolic disorders or myelosuppression have become more and more conspicuous [11, 12]. Therefore, the development of effective and low-cost therapeutics is of high importance and necessity for patients with IBD.

Due to limited effective medications and concerns of side effects, the estimated prevalence of patients with IBD in North America and Europe using complementary and alternative medicines (CAM) has ranged from 21 to $60 \%$, ranking among the highest users of CAM $[13,14]$. Chinese medicine $(\mathrm{CM})$ as one of the most developed branches of CAM has been widely used to treat IBD. Substantial studies have revealed that CM and many CMderived active constituents, such as rutin, quercetin, resveratrol, curcumin and berberine, can effectively reduce the intestinal inflammation and promote the wound healing through multiple mechanisms $[15,16]$. Although the application of a majority of CM or their extracts has achieved decent therapeutic efficacy in experimental IBD models [17-20], the widely use of CM is severely limited because of poor water-solubility, instability at different environmental factors, and short half-life.

Novel drug delivery systems (DDS), which enclose therapeutic drugs in different preparations through a series of nanotechnology and excipients, have revolutionized the treatment of IBD in recent years. Novel DDS can be engineered to improve the solubility and stability, increase the bioavailability, control the drug release rate, increase the accumulated concentration at the desired site and reduce the systemic toxicity of the drugs [21]. Varieties of DDS are designed according to the physiological and pathological features of IBD, which is characterized by the change of $\mathrm{pH}$, gastric empty time, unique enzymes and micro-flora, higher pressure and overexpression of specific proteins. The emergence of novel DDS has provided new platforms for $\mathrm{CM}$ to exert their potentials in treatment of IBD and relieve the related symptoms of IBD [22, 23]. Here, the rationale of this review is to summarize the DDS developed in the past and present to deliver CM for the treatment of IBD.

\section{The complex pathogenic mechanisms of IBD}

Nowadays, IBD is recognized as a chronic relapsing intestinal inflammation with unknown etiology and pathogenesis. People with IBD could suffer from the course of episodic or persistent symptoms, as well as recurring bowel trouble. Generally, it is worldwide accepted that a complex interaction between the genetic, environmental, microbial and immunological factors involves in IBD pathogenesis [24]. Among four components, immune disorders are considered to be the most essential factor contributing to the development of IBD. The dysregulation of intestinal epithelial barrier indicates the incidence of IBD.

Over the past decades, rapid successes in genetic analysis and sequencing uncover more and more IBD-related/ causing genes and pathways. These genes and signaling pathways mainly implicated in the maintenance of intestinal homeostasis, such as mucus barrier (GNA12, HNF4A, CDH1, MUC19), epithelial restitution (REL, PTGER4, STAT3, ERRFI1), regulation of innate immune (CCL11, CCL2, CCL7, MST1), autophagy (ATG16L1, $X B P 1, N O D 2, L R R K 2, C U L 2, I R G M)$ and adaptive immunity (NDFIP1, TNFSF8, TAGAP, IL2, IFNG, IL5, IL7R, IRF5, IL10, IL27, CREM), IL-23/ $\mathrm{T}_{\mathrm{H}} 17$ signaling (IL23R, JAK2, IL21, TNFSF15), endoplasmic reticulum (ER) stress (CPEB4, ORMDL3, SERINC3, XBP1) [25]. Recently, the largest genetic association studies and transethnic analysis documented about 200 susceptibility loci and over 300 potential genes for IBD [26]. However, these identified genetic factors and susceptibility loci disclosed so far account for only $20-25 \%$ of the genetic risk of IBD. In addition, several environmental factors play risky roles in the pathogenesis of IBD, including smoking, diet, some nonsteroidal anti-inflammatory drugs (NSAIDs), antibiotics, social stress or psychological element [24]. Although the relationships among them remain poorly understood, accumulating evidences have shown that smoking and drugs, including NSAIDs and antibiotic, have significant impacts on triggering onset or relapse of IBD, while high levels of stress and the psychological changes from perceived stress could partly medicate the deterioration of IBD [27-32]. Furthermore, many studies have established the association between the changes in intestinal microbiota and IBD. A significant reduction in biodiversity and stability of gut microbiota and a marked increase in adherent and invasive bacteria have been found in patients with IBD in comparison with that of healthy people [33-36].

Currently, more and more efforts have been dominated in investigating the relationships between gut inflammation and IBD pathogenesis. The dysfunctions of innate and adaptive immune signaling have been well-documented to play crucial roles in contributing to the abnormalities of gut inflammatory response in IBD. Immunological studies focused on innate immune responses in IBD show the importance of epithelial barrier integrity, innate microbial sensing and autophagy in contributing to IBD pathogenesis [37-40]. On the other hand, most recent studies indicated that $\mathrm{CD}$ has been associated with an aberrant Th1 response-driven gut inflammation while UC has been mediated by a non-conventional Th2 immune response in gut when it comes to an adaptive immune response in IBD [41]. 
Taken together, these components are responsible for IBD, which facilitated by defects in the intestinal epithelial barrier, causing innate and adaptive immune response with a large amount of cytokines, and then leading to the activation of subclinical or acute mucosal immune system, eventually resulting in an active and chronic inflammation and tissue destruction like fibrosis, abscess, fistula, and even cancers.

\section{Therapeutic potential of $\mathrm{CM}$ for the treatment of IBD}

In recent years, various $\mathrm{CM}$ and $\mathrm{CM}$-derived active constituents have been employed in the treatment of IBD and displayed great potential and effectiveness from bench to clinical application. It has been reported that $\mathrm{CM}$ can be used to treat a series of acute and chronic gastrointestinal diseases by clearing body heat and dampness, detoxifying, and invigorating the circulation of blood [42, 43]. Notably, CM is appealing more and more attention and investigation in the treatment of IBD due to the potential benefits of high acceptance by patients, less undesirable side effects, and relatively low cost. The existing CM for the treatment of IBD can be classified according to preclinical drugs, drugs in clinical trials, and listed drugs. Some of the drugs currently in preclinical studies are described below, and there are many others that have not been mentioned in this article. Periplaneta Americana, a medicinal insect, its ethanol extract could attenuate the dextran sulfate sodium (DSS)-induced UC in rats, by means of ameliorating intestinal inflammation, improving intestinal barrier function, and regulating the disturbed gut microbiota, modulating the flora structure, and restoring the intestinal immune system [44]. Wedelia chinensis, the whole grass of Wedelia chinensis (Osbeck) Merr, can significantly ameliorate the symptoms of colitis in animal models, such as diarrhea, rectal bleeding and weight loss, reduce colonic atrophy and histopathological damage caused by inflammation [45]. Tanshinone IIA, the major active lipophilic components of Danshen, and Notoginsenoside R1, the main bioactive component of Panax Notoginseng, could both attenuate experimental inflammatory bowel disease via pregnane $\mathrm{X}$ receptor activation $[46,47]$. Several CM products have been introduced to trials of IBD patients after passing animal studies successfully. In UC, aloe vera gel, tormentil extracts, wheat grass juice (Triticum aestivum), Andrographis paniculata extract (HMPL-004) and topical Xilei-san were better to placebo in inducing remission or response, and curcumin was superior to placebo in maintaining remission [48-53]. In CD, Artemisia absinthium (wormwood) and Tripterygium wilfordii were superior to placebo in inducing remission and preventing clinical recurrence of post-operative $\mathrm{CD}$ respectively $[54,55]$. A multicenter study showed that the efficacy of Andrographis paniculata (HMPL-004) was as potent as mesalazine after an 8 -week therapy in mild-to-moderate UC patients, thus indicating that HMPL-004 is a promising alternative to mesalazine in UC [56]. In a randomized, placebo-controlled trial, 39 adult postoperative $C D$ patients were treated with Tripterygium wilfordii (TW) or SASP for 2 weeks. The recurrence rate of CD in the TW treated group was significantly lower than that in the SASPtreated group [54]. CM that have been introduced into the market for the treatment of IBD are mainly compound preparations, including Gubenyichang Tablets, Bupiyichang Pills, Guchang Zhixie Pills, Changweining Tablets and Shenqi Baizhu Pills, etc. Therefore, the therapeutic potential of CM in the IBD therapy is large and the development of advanced CM or CM-derived formulations is promising.

\section{Novel DDS of CM for the treatment of IBD}

Substantial CM are found to have potent anti-inflammatory effects, but their wide application into clinic was challenged due to poor water-soluble ability, instability and rapid metabolism. Fortunately, nanotechnology and related technologies advanced the development of novel DDS and thus addressed these problems to some extent. In this section, the following DDS were introduced to overcome undesirable features of $\mathrm{CM}$, such as nanoparticle, self-nanoemulsifying DDS (SNEDDS), nanoemulsion, nanosphere, nanotube, solid lipid microparticle, capsule and lipid-based nanocarriers.

\section{pH-dependent DDS}

The $\mathrm{pH}$ of GIT is elevated from the stomach to the colon. The $\mathrm{pH}$ value of the colon can be achieved 7.0-7.4 and this character can be exploited to design a $\mathrm{pH}$-dependent DDS to specifically release the drug in the colon inflammation site [57]. The most commonly used carrier material for $\mathrm{pH}$-dependent drug carriers is the acrylate copolymer (Eudragit). It is an anionic polymer in which the carboxylic acid group does not dissociate at a low $\mathrm{pH}$ and is therefore insoluble in the stomach. After entering the small intestine, the polymer molecules become ionized and gradually dissolve as the $\mathrm{pH}$ increases [58]. The greater the proportion of carboxyl groups in the molecule, the higher the $\mathrm{pH}$ required for dissolution. Several Eudragit-based products have been approved as pharmaceutical excipients to achieve $\mathrm{pH}$-dependent drug release in the colon, currently.

Silybin is a flavonolignan and extracted from the seeds of Silybum marianum L. Since ancient times, it has been used for the treatment of various gastrointestinal and liver diseases, which is attributed to its radical scavenging activities [59]. Eudragit RL PO NPs were prepared 
using solvent evaporation emulsification technique and then were coated by Eudragit FS30D to deliver silybin in the inflamed intestinal site. Animal experimental results demonstrated the significant reduction of TNF- $\alpha$, IL-6 and myeloperoxidase (MPO) activity and the amelioration of macroscopic and histopathological scores by the optimized NPs in the acetic acid-induced rat colitis model compared to control group [60].

Curcumin is a bioactive polyphenol isolated from the rhizome of the Curcuma longa L. (turmeric) [61, 62]. Extensive researches on curcumin have proven that it is a molecule with anti-oxidant, anti-inflammatory and antitumorigenic properties [63-65]. As a BCS IV drugs, the solubility and permeability of curcumin are both poor. The microsponge of curcumin was developed by quasi emulsion solvent diffusion method. Release studies revealed that microsponges prevented the premature release of curcumin in upper GIT and specifically released curcumin at colonic $\mathrm{pH}$. Pharmacodynamic study demonstrated that, compared to free curcumin, curcumin microsponges can ameliorate edema, necrosis, and hemorrhage of colon. In addition to microsponge, curcumin-loaded poly (lactic-co-glycolic acid) (PLGA) $\mathrm{NP} /$ microparticle and microsphere (zein and PVMMA) [66-68] were prepared and then coated with $\mathrm{pH}$-sensitive materials Eudragit S100 and FS30D. In vitro and in vivo assays of the three curcumin-loaded DDS exhibited $\mathrm{pH}$ dependent release behavior and delivered curcumin to the colon lesion to exert excellent anti-inflammation efficacy [69].

Rutin is a citrus flavonoid glycoside found in many plants. Like other flavonoid compounds, rutin possesses strong anti-oxidant activity. So starch and acrylic acid were copolymerized using the direct gamma radiation technique to form the hydrogel and then encapsulated rutin. In vitro release of rutin-loaded hydrogel revealed strong $\mathrm{pH}$-dependent release behavior. The reduction of colon/body weight ratio, MPO activity, TNF- $\alpha$, nitric oxide and histopathological results confirmed the efficacy of the poly (starch/acrylic acid) hydrogel loaded rutin [70]. Ellagic acid, a natural phenol, has the antiproliferative and antioxidant properties. The microsphere of ellagic acid was prepared using a $\mathrm{pH}$-sensitive polymer, Eudragit P-4135F, carmellose sodium and Span 80. Release behavior suggested that the $\mathrm{pH}$-responsive microsphere was prepared successfully and can be used to deliver drug in the colon for the treatment of IBD [71].

Shikimic acid (SA), more commonly known as its anionic form shikimate, affects arachidonic acid metabolism, inhibits platelet aggregation, inhibits arterial and venous thrombosis, and has anti-inflammatory effects. Butyric acid (BA), a short chain fatty acid, has good therapeutic effects on UC confirmed by many experiments.
But the short half-life of oral administration limited its application. 3,4,5-Tributyryl shikimic acid (TBS), a novel prodrug, was synthesized through an ester bond between SA and BA. Amberlite 717, the anion-exchange resin, was employed as the carrier to encapsulate TBS through the ion-exchange reaction. Simultaneously, Eudragit S100, the enteric coating material, was introduced to encapsulate the drug-loaded resin to form the drug-loaded resin microcapsule (TBSS-DRM). The TBSS-DRM exhibited a good therapeutic effect on 2,4,6-trinitrobenzenesulfonic acid (TNBS)-induced experimental colitis mouse [72]. Rectal administration of Piceatannol, an analog and metabolite of resveratrol, by colon-targeted capsule also ameliorated rat colitis and reproduced the molecular effects in the inflamed colonic tissues [73].

\section{Time-delayed and pressure-dependent DDS}

Although the gastric emptying time is extremely irregular, the transit time of the material in the small intestine is relatively constant, usually 3 to $4 \mathrm{~h}$ [74]. Based on this feature, a time-delayed colon targeting system was designed to ensure that the drug began to release after 3 to $4 \mathrm{~h}$ of leaving the stomach. At present, it is common to encapsulate drugs with poorly soluble coating materials that are difficult to decompose. Adjusting the proportion and amount of material is used to control drug release time.

Acetylharpagide, extracted from Ajuga decumbens, is widely used for remedying infectious and inflammatory diseases in Southern China. But it can be destroyed by the stomach acid due to the hemiaceta structure. Acetylharpagide tablets were formulated with the dual mechanism, pH-dependency and time-delay release. The core tablets were coated with the ethyl cellulose and suitable channeling agent followed by coating with $\mathrm{pH}$ dependent polymers. In vitro drug release and the pharmacokinetic evaluation in dogs showed that acetylharpagide colontargeted tablets could target the drug to the colon [75].

There are peristaltic waves in the GIT of the body, but a large amount of small intestinal fluid in the small intestine can effectively buffer the intracavity pressure, and the intracavitary pressure of the intestinal contents is reduced. However, the colon absorbs a large amount of liquid, the contents solidify, and the intracavitary pressure is increased in the colon [76]. Pressure-controlled DDS are constructed to bear up against luminal pressure in the small intestine, but to collapse at the higher colonic pressure with a final drug release in the colon 3-7 $\mathrm{h}$ after peroral administration. Usually, the preparation of pressure-dependent DDS is based on the coating of gelatine capsules with ethyl cellulose. To date, there is no report 
about the pressure-dependent DDS for the delivery of CM to treat IBD.

Variation in GI transit times, altered gastro-intestinal motility and water absorption in IBD may limit the therapeutic benefits of these two types DDS. The change of transit times and pressure in IBD patients should be furtherly investigated and discussed to guide a definite direction. More pharmaceutical investigations for timedelayed and pressure-dependent DDS of CM are essential to evaluate the therapeutic potential for the therapy of IBD.

\section{Enzyme/microbiota-activated DDS}

The human colon begins with the cecum and ends with the rectum. The physiological structure is divided into four parts, namely ascending colon, transverse colon, descending colon and sigmoid colon. The colon is mainly used to absorb water and electrolytes, store the body's metabolites, solidify them into feces, and excrete them through the rectum. At the same time, the colon also provides a suitable living environment for the inside microorganisms. Studies have shown that the colon is rich in more than 400 beneficial bacteria, and the bacteria in the colon fluid is about $1 \times 10^{11} / \mathrm{mL}$, which forms a very large flora gradient with the small intestine. In the colon, these bacteria can produce a large number of highly active proteolytic enzymes and peptidases, which can catalyze many metabolic reactions. The anaerobic environment in which the colon is located makes the enzymatic reaction at the colon mainly degradation [77-79]. Using a material that can be degraded by enzymes specific to the colon (such as azo degrading enzyme, glycosidase, pectinase, etc.) as a targeting carrier material, the formulation is degraded and the drug can be released and then absorbed by the colon site to increase the bioavailability of the drugs.

Rutin pellets were successfully prepared and showed very good characteristics. Pellets presented desirable rutin dissolution profiles and excellent stability when coated with sodium alginate/chitosan. The combination of rutin chitosan, sodium alginate and pellets could form a promising preparation free of side effects for life-long therapy of IBD [80].

Resveratrol is also a polyphenol bioactive agent present in vegetables, fruits and plants and it has various biological activities, such as antitumor, antiviral and antioxidant effect [81]. However, rapid absorption and extensive metabolism in the liver and gastrointestinal tract lead to its low oral bioavailability [82]. Ca-pectinate beads were designed to deliver resveratrol in the treatment of IBD. Animal experiments showed that the lowest disease activity index (DAI) and histopathological score have been recorded in the group treated by Ca-pectinate beads and the anti-inflammatory effects of resveratrol could be attributed to its inhibitory effect on sphingosinekinase 1 (SphK1) [83].

Icariin, isolated from CM Horny Goat Weed (Epimedium alpinum L.), is commonly used by mouth for sexual performance problems and inflammation-related diseases. The poor solubility and low bioavailability limited its application in the clinic [84]. Alginate-chitosan microspheres loaded with icariin were investigated in TNBS/ethanol-induced colonic mucosal injury rats. Pharmacodynamics studies indicated that it could not only reduce the colonic injury, but also inhibit the inflammatory response in colonic mucosa [85].

To achieve colon targeted delivery, chitosan and nutriose were coated on the surface of the quercetin nanovesicles. A marked amelioration of symptoms of TNBS-induced colitis was observed in animals treated with quercetin-loaded coated vesicles, favoring the restoration of physiological conditions [86].

Curcumin polymer (polycurcumin, PCur) was synthesized through disulfide bond between hydrophilic PEG and hydrophobic curcumin (Fig. 1). PCur led to preferential accumulation of curcumin in the inflamed regions owing to the good solubility, proper size and neutral properties. Moreover, from the release curve, we can observe a significantly elevated release of curcumin when responding to a bacterial reduction in the colon. Finally, in DSS-induced murine model of IBD, orally administered PCur ameliorated the inflammatory progression and could protect mice from IBD [87]. Novel polyacrylamide-grafted-xanthan gum (PAAm-g-XG) NPs were prepared for colonic delivery of curcumin. Release studies indicated microflora-dependent drug release property of NPs. Curcumin NPs reduced nitrite and myeloperoxidase levels, prevented weight loss and attenuated colonic inflammation in acetic acid-induced IBD in rats [88].

Sinomenine, a pure alkaloid extracted from Sinomenium acutum (Thumb.) Rehd. et Wils., is widely known for its anti-inflammatory and immunosuppressive effects [89]. Due to its low oral bioavailability, chitosan microspheres coated by Eudragit were prepared to delivery sinomenine to the colon lesion for IBD therapy. In DSSinduced experimental colitis, DAI of the sinomenine enteric-coated microspheres-treated group was significantly lower than that of the SASP-treated group, which might be attributed to the suppression of the TLR/NF- $\mathrm{kB}$ signaling [90]. Similarly, curcumin (CN)-containing chitosan NPs (CS-NPs) coated with Eudragit FS30D were prepared by ionic gelation and solvent evaporation method. In vivo distribution revealed good accumulation of CS-NPs in the colonic region [91]. 


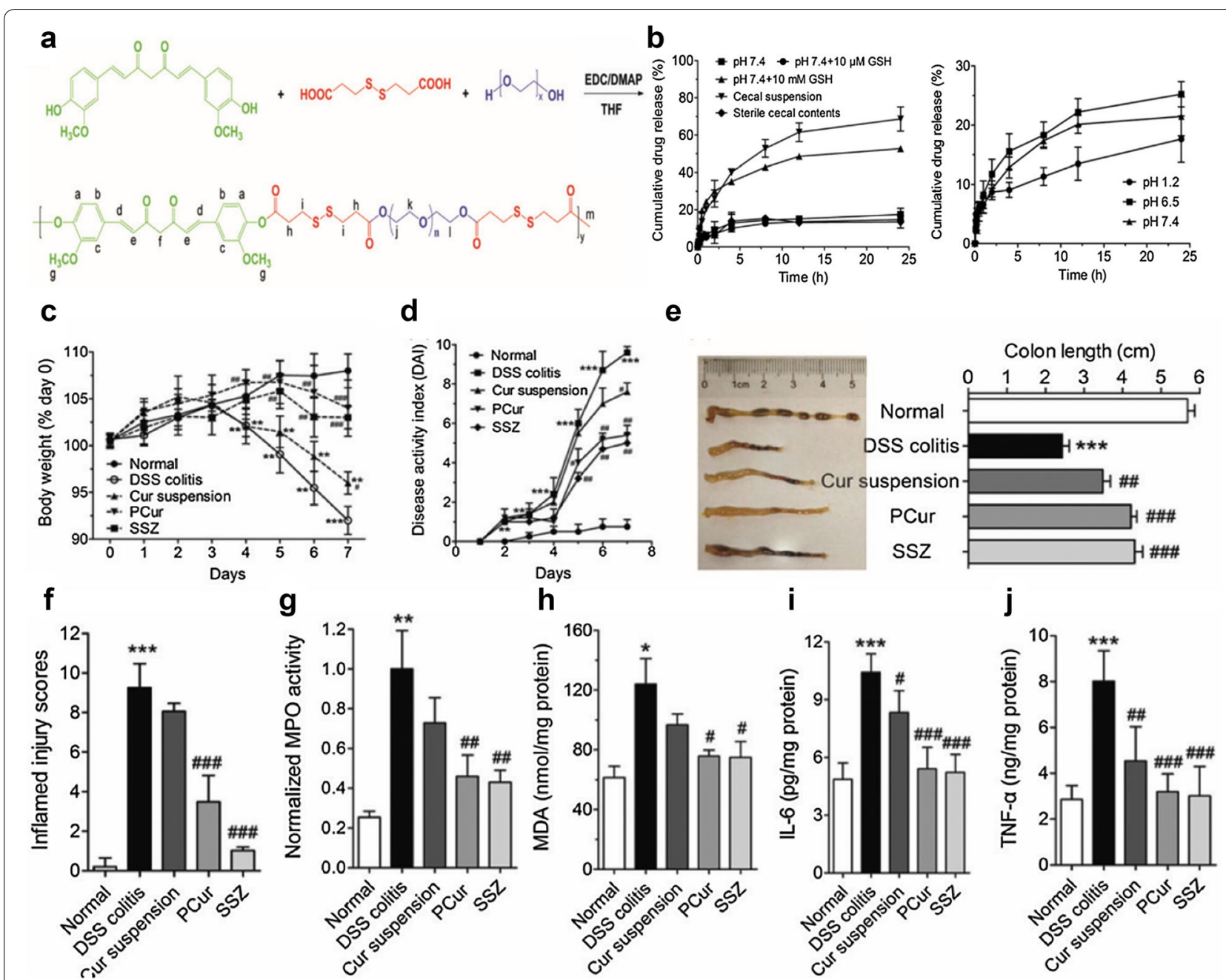

Fig. 1 Polycurcumin conjugate for the treatment of IBD. a Synthetic scheme of polycurcumin conjugate. $\mathbf{b}$ In vitro release behavior in the different conditions. c Change in body weight, d DAl evaluation. e Colon length of normal mice and DSS-induced mice receiving different treatments. $\mathbf{f}$ Quantitative scores of inflamed degree. $\mathbf{g}$ MPO activity, $\mathbf{h}$ MDA. $\mathbf{i}$ IL- 6 and $\mathbf{j}$ TNF-a levels in colonic tissues after administration of polycurcumin (Reprinted with permission from Ref. [87]. Copyright Taylor and Francis Online 2016)

From the above examples, it is not difficult to see that chitosan and sodium alginate are used as the main carrier materials of enzyme-sensitive (mucoadhesive) colontargeted DDS to deliver CM for the treatment of IBD. Therefore, for the specific azo reductase and disulfide reductase in the colon, the DDS by connecting disulfide bonds and azo bonds between the drug and the carrier would be a good choice to treat IBD.

\section{Co-delivery systems for the treatment of IBD}

Co-delivery of different kinds of drugs can overcome the unsatisfactory disadvantage and improve therapeutic efficacy through synergistic interaction. CD98 is highly overexpressed on epithelial cells and macrophages in the colon tissue under mucosal damage and inflammation.
Previous research has proved that siRNA targeting CD98 (siCD98) could decrease the severity of UC by downregulating the expression of $\mathrm{CD} 98$ in colitis tissue. Hyaluronic acid (HA)-functionalized NPs can realize targeted delivery of siCD98 and curcumin to colonic epithelial cells and macrophages (Fig. 2). Furthermore, siCD98 and curcumin can synergistically prevent mucosal damage and reduce inflammation [92].

Piperine (PIP), an important bioactive compound of black pepper, could inhibit metabolizing enzymes, retard clearance rate of $P$-glycoprotein (P-gp) efflux pump and downregulate the expression of NF- $\mathrm{KB}$, thus enhancing the absorption of curcumin and protecting against oxidative damage. Treatment with CUR-PIP-SMEDDS has an equivalent effect to 5-ASA 


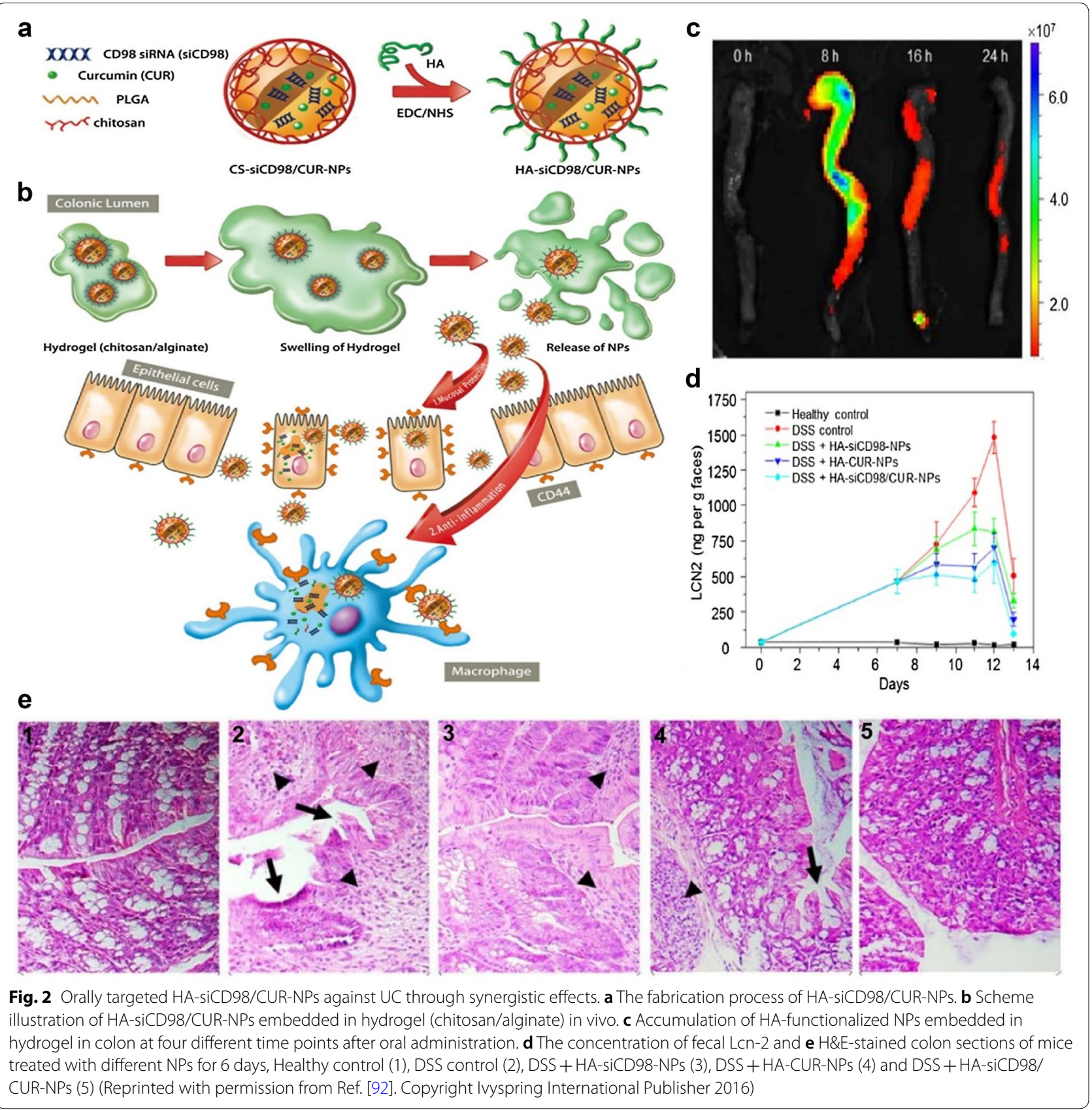

in maintaining remission of $\mathrm{UC}$ by retention enema administration. In addition, it could directly interact with the inflamed epithelium tissue of the mice colon and release curcumin immediately to increase the local concentration in colonic lesion site [93]. In a similar way, thiolated chitosan/alginate composite microparticulates (CMPs) coated by Eudragit S-100 were developed for colon-specific delivery of 5-ASA and curcumin. The combination of $\mathrm{pH}$-sensitive, mucoadhesion and controlled delivery properties could specifically deliver 5-ASA and curcumin to the site of the colon, and markedly alleviate the colon inflammation of colitis rats [94].

Celecoxib, belonging to the nonsteroidal anti-inflammatory drug, is widely used for the treatment of inflammation through inhibiting cyclooxygenase-2 (COX-2) enzyme. But the bioavailability of the drug is poor and it has severe cardiac, gastric and renal toxicity. $\mathrm{pH}$-sensitive NPs loading curcumin and celecoxib were prepared by solvent emulsification evaporation method. This 
local delivery would be more effectively taken up by the colonic milieu, improve their solubility and bioavailability and circumvent the other organ toxicity of celecoxib [95].

\section{Other colon-targeted DDS}

Apart from above mentioned DDS, other delivery systems, including fibroin NPs and SNEDDS, are also exploited and advanced for the treatment of IBD (Table 1). Epigallo-catechin 3-gallate (EGCG) is a natural polyphenol compound extracted from green tea [96, 97]. A large number of studies have shown that it has antioxidant and anti-inflammatory effects. [98]. Moreover, ECGC can relieve the symptoms of colonic inflammation and maintain the integrative structure of intestinal epithelial layer in IL-10 knockout mice [99, 100]. Despite this, its clinical translation has been constrained by limited bioavailability [97]. In a recent study, EGCG-loaded ovalbumin (OVA) NPs were facilely produced via selfassembling method and subsequently were used to treat UC mouse. In vivo results showed that the EGCG-loaded NPs EGCG increased the accumulation of EGCG in colitis tissue sites and showed significantly better therapeutic efficacy in alleviating UC than pristine EGCG [101].

Resveratrol-loaded silk fibroin NPs (RL-FNPs) were prepared through precipitation and incubation methods to overcome its drawbacks. In this DDS, silk fibroin, as a good delivery carrier, harbors the anti-inflammatory and healing effects and could simultaneously enhance the efficacy of resveratrol. The anti-inflammatory effect of RL-FNPs was similar to that of dexamethasone [102]. Similar to resveratrol, quercetin, a potent anti-inflammatory, antioxidant agent [103] was encapsulated into the silk fibroin NPs and the antioxidant activity of quercetin was enhanced due to the synergistic effect of quercetin and silk fibroin [104].

Berberine (BR) is an isoquinoline alkaloid with a long history of medicinal use. BR is usually administered in a salt form for several clinical applications, such as anti-bacterial, anti-inflammatory, and gastrointestinal diseases [105]. However, poor stability and low bioavailability limited the application of BR for long time. Based on the solubility studies and the pseudo-ternary phase diagrams, SNEDDS of berberine was developed using Acrysol K-150, Capmul MCM and polyethylene glycol 400. Chick chorioallantoic membrane and in vivo efficacy assay individually revealed potent anti-angiogenic activity and anti-inflammatory effect of SNEDDS of BR [106]. Bruceine $\mathrm{D}(\mathrm{BD})$ is a natural quassinoid derived from $\mathrm{B}$. javanica fruit and has various pharmacological activities including anti-cancer, anti-virus and anti-inflammatory effects [107]. However, the low solubility of BD is a barrier for its absorption and release, which results in poor bioavailability. To address this problem, SNEDDS of BD was developed and composed of MCT, solutol HS-15, propylene glycol. According to the pharmacokinetic statistics, pharmacokinetic parameters of BD-SNEDDS were enhanced as compared with BD-suspension. In addition, the colon length and body weight were significantly restored, and TLR4, NF- $\mathrm{kB}$ p65 protein expressions were suppressed in TNBS-induced UC rat model [108]. Different from SNEDDS, the composition of nanoemulsion (NE) increased water phase. Andrographolide (AG) is a natural diterpenoid isolated from Andrographis paniculata. Previous studies have shown that it has been utilized extensively for the treatment of IBD, because it can inhibit TNF- $\alpha$, IL-1 $\beta$, and NF-KB activities [109]. However, the low oral bioavailability seriously limited its application in the treatment of IBD [110]. AG-NE was prepared using high-pressure homogenization technique and composed of $\alpha$-tocopherol, ethanol, cremophor EL, and water. In the pharmacokinetic assay, the bioavailability of AG from AG-NE was almost six times in comparison with that from the AG suspension [111].

Embelin is a benzoquinone derivative found in Ardisia japonica. It is reported that embelin targets microsomal prostaglandin E2 synthase (MPGES) and eicosanoid synthesizing proteins 5-lipoxygenase (5-LO), thus exhibiting potent anti-inflammation effect [112]. Embelin lipid nanospheres (LNs) were developed by hot homogenization followed by ultrasonication technique. Treatment with embelin LNs significantly reduced clinical activity and macroscopic scores compared to embelin conventional suspension in acetic acid-induced UC rat model. Meanwhile, MPO, lactate dehydrogenase (LDH) and lipid peroxides (LPO) levels were decreased and reduced glutathione (GSH) level was increased [113].

Anthocyanins are sugar conjugates of flavonoids and they are prevalent in flowers, fruits, and vegetables. Numerous studies have shown that anthocyanin-rich berries provide strong antioxidants and anticarcinogenic properties. However, poor bioavailability after oral consumption makes it difficult to reach sufficient concentration in the target sites. To increase the concentration of anthocyanins in the colon, three types of encapsulation systems, PA (pectin amide, $\mathrm{CaCl}_{2}$, glycerine), WPI (whey protein isolate) and SL (pectin amide, citric acid maltodextrin, schellac), were developed and evaluated in the simulated gastrointestinal fluid. Release result indicated that encapsulation can potentially stabilize anthocyanins in the GIT [114].

Three kinds of curcumin DDS, including SNEDDS, nanostructured lipid carrier (NLC) and lipid nanocapsules (NC) was conducted to treat IBD. Although the permeability of curcumin across Caco-2 cell monolayers in the NC group was better, another two groups could significantly reduce the secretion of TNF- $\alpha$ secretion in 


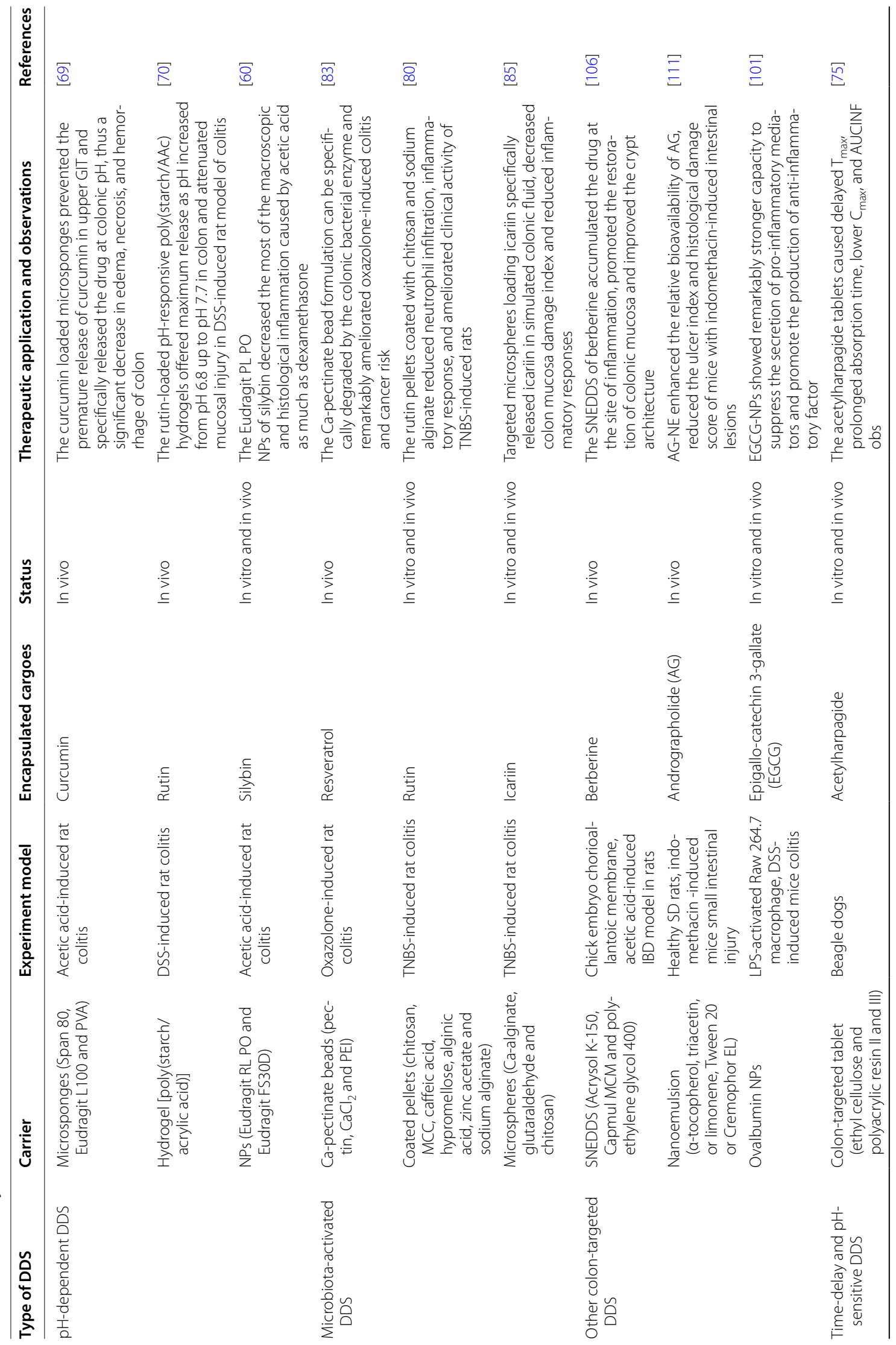




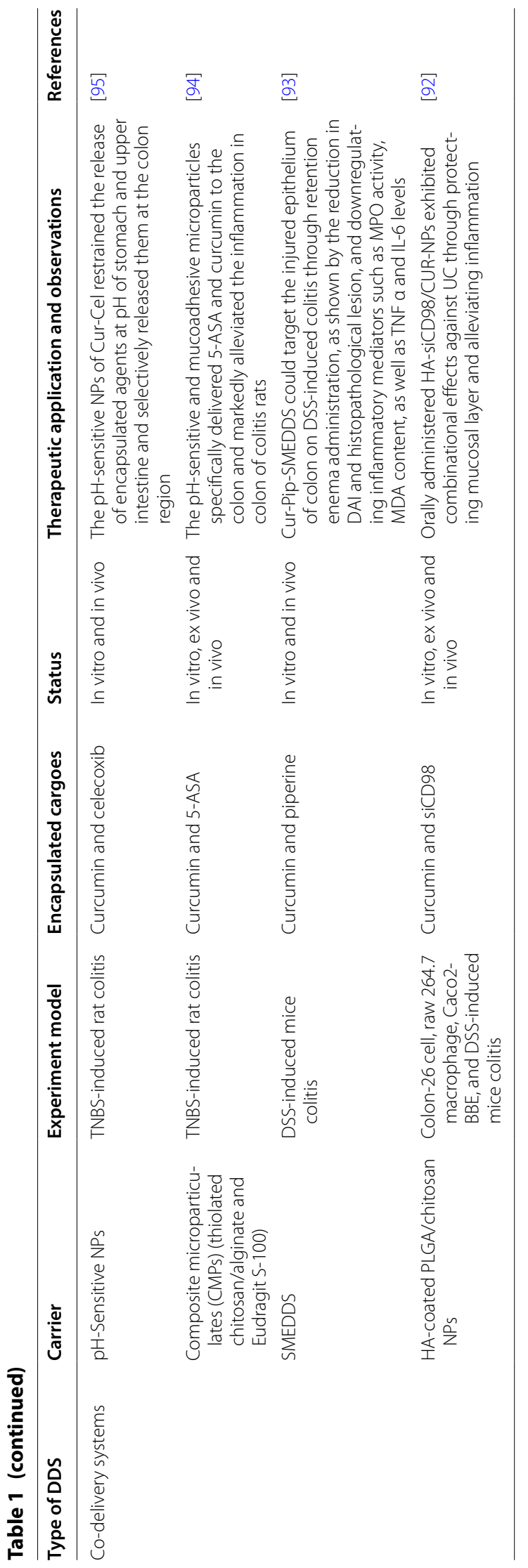


J774 cells. In vivo, decreased neutrophil infiltration and colonic inflammation were only found in the NLC group [115]. Another study prepared curcumin-loaded solid lipid microparticle (SLM) and investigated anti-inflammatory activity using rat colitis models. Rat treated with curcumin-loaded SLM showed faster weight gain and an increase of the whole colon length compared with DSSinduced rats [116].

\section{CM-based DDS for the treatment of IBD Ginger-derived DDS for the treatment of IBD}

Ginger, derived from the rhizome of Zingiber officinale Rosc., is consumed as a spice and also used as an alternative medicine for a range of disorders like cold, fever, as well as many digestive tract problems like diarrhea and dyspepsia [117]. Studies have also shown that ginger and its active constituents, such as 6-gingerol and 6-shogaol, exhibit anti-oxidative, anti-inflammatory, and anti-cancer activities [118]. It is reported that a kind of NPs derived from edible ginger (GDNPs) exhibited efficient colon targeting following oral administration. GDNPs could also increase the survival and proliferation of intestinal epithelial cells (IECs), reduce the proinflammatory cytokines (TNF-a, IL- 6 and IL-1 $\beta$ ), and increased the anti-inflammatory cytokines (IL-10 and IL-22) in colitis models, suggesting that GDNPs has the potential to attenuate damaging factors while promoting the healing effect [119].

In addition, ginger-derived nanolipids are also developed as carrier material for the delivery of siRNA to treat UC. Ginger-derived lipid vesicles can encapsulate siCD98 and a very low dose of siCD98 after oral administration can specifically and efficiently reduce colonic CD98 gene expression [120]. Even the researcher suggested that siCD98/GDLVs have the potential to shift the current paradigm of siRNA delivery away from artificially synthesized NPs toward the use of naturederived nanovectors from edible plants. 6-shogaol, the active ingredient of dried ginger, was loaded with folatefunctionalized PLGA/poly-lactic acid (PLA) NPs using a versatile single step surface-functionalizing technique [121]. In vivo results showed that oral administration of NPs-PEG-FA/6-shogaol in a hydrogel system (chitosan/ alginate) significantly alleviated colitis symptoms and accelerated colitis wound repair in DSS-treated colitis mice, by regulating the expression levels of proinflammatory (TNF- $\alpha$, IL-6, IL- $1 \beta$, and iNOS) and antiinflammatory (Nrf-2 and HO-1) factors. Here, folic acid, a ligand for folate receptor which is overexpressed in IBD, was modified on the surface of the carrier to achieve colonic targeted delivery of the drug. In 2012, grape exosome-like NPs (GELNs) were proved by Zhang's group that it can promote the intestinal tissue remodeling and protect against DSS-induced colitis [122]. Six years later, the group found that ginger exosome-like NPs (ELNs) are preferentially taken up by gut bacteria in an ELN lipid-dependent manner. ELN RNAs regulate gut microbiota composition and localization as well as host physiology, notably enhancing gut barrier function to alleviate colitis. More substances consisting of natural plants will be found and can be used for the treatment of IBD as therapeutic agents, drug carrier or both [123].

\section{CM-derived polysaccharide as drug carrier for the treatment of IBD}

In recent years, polysaccharides are attracting more and more attention as a new class of colon targeting materials. Polysaccharides are usually not absorbed in the upper part of the digestive tract (stomach and small intestine), but can be specifically degraded by colon bacteria. As natural products, polysaccharides are not only cheap and easy to obtain, while their safety has been proven for long time and collected as a pharmaceutical excipient in various national pharmacopoeias [124]. Such compounds mainly include amylose, dextran, pectin, guar gum and chondroitin sulfate. In addition to the above polysaccharide macromolecules, other natural polysaccharides from $\mathrm{CM}$ were also developed to achieve colon-target drug delivery.

Angelica polysaccharide was extracted from fresh roots of Angelica sinensis. (Oliv.) Diels, which has been used as a CM to treat various diseases for thousands of years. There is mounting evidence revealing that Angelica polysaccharide possesses anti-ulcer and immunomodulation capabilities [125]. Zhou et al. chose Angelica polysaccharide as a drug carrier and succinate as a cross-linker, then dexamethasone (Dex)-polysaccharide conjugate was synthesized [126]. The newly synthesized dexamethasonepolysaccharide conjugate was found to greatly reduce the systemic immunosuppression caused by Dex and effectively convey Dex to the large intestine. Furthermore, the conjugate also showed promising therapeutic effect on TNBS-induced UC in rats.

Psyllium, viscous polysaccharides derived from the dried, ripe seeds of Plantago genus, has been reported as a medicinally active natural polysaccharide and used for the treatment of constipation, diarrhea, irritable bowel syndrome (IBS), UC, colon cancer, diabetes and hypercholesterolemia [127]. Due to its biodegradability and digestibility, psyllium is rapidly emerging as a low-cost drug carrier and has been verified in some researches [128]. Inulin, consisting of linear polydisperse chains of $\beta(2,1)$ fructan, is another natural polysaccharide derived from natural plants. The presence of $\beta(2,1)$ bonds in inulin prevents its degradation in the stomach and small intestinal. Abundance of hydroxyl groups makes it easy 
to interact with common coupling reagents [129]. A novel amphiphilic inulin by grafting it with a hydrophobic peptide can enable the resulting conjugate to self-assemble into nanostructures and then encapsulate therapeutic agents [130]. Another amphiphilic inulin derivative was developed by Sun et al. and was used to specifically deliver budesonide to the inflamed colon tissue [131]. Besides, Ulva lactuca (ULP) polysaccharide displays several biological features like lowering cholesterol, immunomodulatory and anti-heptotoxic property [132]. ULP can also stabilize the functional status of biomembranes and act as an antioxidant compound and surfactant. Selenium (Se) is an essential micronutrient trace element and low Se status has been demonstrated in association with IBD progression. Se NPs (SeNPs) exert anti-inflammatory activity accompanied by low toxicity, especially when decorated with natural biological compounds. SeNPs decorated with Ulva lactuca polysaccharide (ULP) can mitigate body weight loss and colonic inflammatory damage on DSS-induced acute colitis in mice [133].

\section{CM as gas donors for the treatment of IBD}

Gases such as nitric oxide, carbon monoxide and hydrogen sulfide play important roles in human physiological processes. Previous studies prepared styrene-maleic acid copolymer (SMA) micelles encapsulating tricarbonyldichlororuthenium (II) dimer (CORM2), a commonly

Table 2 CM-based DDS for the treatment of IBD

\begin{tabular}{|c|c|c|c|c|c|}
\hline Carrier & Experiment model & Encapsulated cargoes & Status & $\begin{array}{l}\text { Therapeutic application } \\
\text { and observations }\end{array}$ & References \\
\hline NPs derived from ginger & $\begin{array}{l}\text { DSS-induced colitis mouse } \\
\text { model }\end{array}$ & - & In vitro and in vivo & $\begin{array}{l}\text { Oral administration of } \\
\text { GDNPs increased the } \\
\text { survival and proliferation } \\
\text { of IECs, reduced pro- } \\
\text { inflammatory cytokines, } \\
\text { and increased the anti- } \\
\text { inflammatory cytokines in } \\
\text { colitis models }\end{array}$ & {$[119]$} \\
\hline NPs derived from ginger & $\begin{array}{l}\text { Colon-26 and RAW } 264.7 \\
\text { cells, normal mice }\end{array}$ & siCD98 & In vitro and in vivo & $\begin{array}{l}\text { Ginger-derived lipid vesicles } \\
\text { can encapsulate siCD98 } \\
\text { and a very low dose of } \\
\text { siCD98 after oral admin- } \\
\text { istration specifically and } \\
\text { efficiently reduced colonic } \\
\text { CD98 gene expression }\end{array}$ & {$[120]$} \\
\hline Angelica polysaccharide & TNBS-induced UC in rats & Dexamethasone (Dex) & In vivo & $\begin{array}{l}\text { The Angelica polysaccha- } \\
\text { ride-Dex conjugate greatly } \\
\text { reduced the systemic } \\
\text { immunosuppression } \\
\text { caused by Dex and effec- } \\
\text { tively conveyed Dex to the } \\
\text { large intestine }\end{array}$ & {$[126]$} \\
\hline Inulin & $\begin{array}{l}\text { DSS-induced colitis mouse } \\
\text { model }\end{array}$ & Budesonide & In vivo & $\begin{array}{l}\text { The redox-sensitive NPS, } \\
\text { based on amphiphilic } \\
\text { inulin, specifically deliv- } \\
\text { ered budesonide to the } \\
\text { inflamed colon tissue and } \\
\text { exerted excellent thera- } \\
\text { peutic efficacy in compari- } \\
\text { son to drug suspension in } \\
\text { colitis mice model }\end{array}$ & {$[131]$} \\
\hline $\begin{array}{l}\text { In situ self-spray coating } \\
\text { system (DTPA dianhydride, } \\
\text { SBC, SDS) }\end{array}$ & $\begin{array}{l}\text { Caco- } 2 \text { cells, raw } 264.7 \\
\text { macrophage, DSS-induced } \\
\text { rat colitis }\end{array}$ & Diallyl trisulfide (DATS) & In vitro and in vivo & $\begin{array}{l}\text { Rectal administration of the } \\
\text { DATS-loaded self-spray sys- } \\
\text { tem produced exogenous } \\
\mathrm{H}_{2} \mathrm{~S} \text { and suppressed the } \\
\text { overproduction of pro- } \\
\text { inflammatory cytokines, } \\
\text { inhibited the adhesion } \\
\text { of macrophages on the } \\
\text { vascular endothelium, and } \\
\text { repaired colonic inflamed } \\
\text { tissues }\end{array}$ & {$[136]$} \\
\hline
\end{tabular}


used $\mathrm{CO}$ donor, and evaluated the therapeutic potential of SMA/CORM2 in DSS-induced inflammatory colitis murine model [134]. After treatment with SMA/CORM2 micelles, colitis symptoms (loss of body weight, diarrhea, and hematochezia) and histopathological colonic changes (shortening of the colon and necrosis or ulcers in the colonic mucosa) were significantly improved. It is reported that the first therapeutic-gas NO-responsive hydrogel was prepared and that it may prove useful in many applications, such as drug-delivery vehicles, inflammation modulators, and a tissue scaffold [135]. Hydrogen sulfide $\left(\mathrm{H}_{2} \mathrm{~S}\right)$ is generated throughout the GI tract. Following colonic mucosal inflammation, the synthesis of $\mathrm{H}_{2} \mathrm{~S}$ is significantly increased, accelerating the repair of ulcerative tissues, suggesting that $\mathrm{H}_{2} \mathrm{~S}$ may function as an anti-inflammatory mediator. Diallyl trisulfide (DATS) is an oil-soluble sulfur compound of natural origin that is isolated from garlic. Theoretically, one molecule of DATS can produce three molecules of $\mathrm{H}_{2} \mathrm{~S}$ in the presence of biological thiols, including GSH. However, owing to its insolubility in water, an ideal method of administering DATS has yet to be developed. As an exogenous $\mathrm{H}_{2} \mathrm{~S}$ donor, a self-spray coating system that is derived from a DATS-loaded capsule with foaming capability is prepared. In vivo assay indicated that this system can suppress the overproduction of proinflammatory cytokines, inhibit the adhesion of macrophages on the vascular endothelium, and repair colonic inflamed tissues [136]. The representative examples of CM-based DDS for the treatment of IBD are showed in the Table 2.

\section{Conclusion and future perspectives}

IBD, as a chronic inflammatory disease of the GIT, is common in young people and seriously affects the life quality of patients. As a long-standing cultural treasure, $\mathrm{CM}$ has always been favored by us. However, the unsatisfactory physical and chemical properties of CM have seriously affected their clinical application, and the emergence of various new DDS has solved these problems to some extent. The three major systems of active targeting, passive targeting, and tumor microenvironment-responsive DDS can also be mapped to the drug delivery strategy for IBD. The receptors that are known to be highly expressed in IBD are folate receptor, transferrin receptor, CD44 and CD98 glycoproteins, and more specific receptors are yet to be further explored. Secondly, the changes of various physiological conditions such as $\mathrm{pH}$, temperature, oxygen and enzyme in the colon during the development of IBD are also worthy of further discussion. The existing theory is seriously lacking, which hinders the development of colon-targeted DDS.

One of the critical challenges in the IBD therapy is the drug-related adverse effects. The application of novel
DDS into CM for the treatment of IBD has the potential to accumulate sufficient drug concentration at the disease region, enhance the solubility and bioavailability, prevent drug degradation, thus reducing the administration dose and systemic side effects and maximizing drug efficacy. Although various different functions DDS have been developed and investigated, further studies should be conducted to push good products into the clinic.

Ginger, as a member of CM, has been well developed for the treatment of IBD as therapeutic molecules, lipid nanovectors, and exosomal miRNAs, which could be a model CM worth learning. As an important signal molecule in the physiological process of human body, gas can be used as a therapeutic molecule, and can also be prepared as a gas-responsive DDS to deliver drugs. The components of plants that can be used as donors of such gas molecules are subject to our excavation and research. As a large class of molecules composed of CM, polysaccharides have long been unexplored as drug carriers. More plant polysaccharides as therapeutic drugs for IBD and $\mathrm{CM}$ delivery vehicles will greatly improve the safety and reduce the cost of treatment. For the treatment of IBD, the co-delivery of drugs and the design of prodrugs are also very promising development directions.

\begin{abstract}
Abbreviations
5-ASA: 5-aminosalicylic acid; CAC: colitis-associated cancer; CAM: complementary and alternative medicines; $C D$ : Crohn's disease; $C M$ : Chinese medicine; DATS: diallyl trisulfide; DAl: disease activity index; Dex: dexamethasone; DDS: drug delivery system; DSS: dextran sulfate sodium; EGCG: epigallo-catechin 3-gallate; GIT: gastrointestinal tract; GSH: glutathione; HA: hyaluronic acid; IBD: inflammatory bowel disease; IBS: irritable bowel syndrome; IEC: intestinal epithelial cell; LDH: lactate dehydrogenase; LPO: lipid peroxides; MPO: myeloperoxidase; NPs: nanoparticles; P-gp: P-glycoprotein; PLA: poly-lactic acid; PLGA: poly (lactic-co-glycolic acid); SASP: salicylazosulfapyridine; TNF: tumor necrosis factor; TNBS: 2,4,6-trinitrobenzenesulfonic acid; UC: ulcerative colitis.
\end{abstract}

\section{Acknowledgements}

Not applicable.

\section{Authors' contributions}

SW and YW organized and supervised the study. CG and LL drafted the manuscript and prepared tables and figures. YZ and ZB contributed to revisions of the manuscript. All authors read and approved the final manuscript.

\section{Funding}

This work was supported by the National Key Research and Development Program of China (Grant No. 2017YFE0191500), the Macau Science and Technology Development Fund (Grant No. 0039/2018/A1), and the Research Fund of the University of Macau (Grant No. MYRG2016-00143-ICMS-QRCM).

\section{Availability of data and materials \\ Not applicable.}

Ethics approval and consent to participate

Not applicable.

Consent for publication

Not applicable. 


\section{Competing interests}

The authors declare that they have no competing interests.

\section{Author details}

${ }^{1}$ State Key Laboratory of Quality Research in Chinese Medicine, Institute of Chinese Medical Sciences, University of Macau, Avenida da Universidade, Taipa, Macao, SAR, China. ${ }^{2}$ PU-UM Innovative Institute of Chinese Medical Sciences, Guangdong-Macau Traditional Chinese Medicine Technology Industrial Park Development Co., Ltd, Hengqin New Area, Zhuhai, China. ${ }^{3}$ College of Pharmacy, Chengdu University of Traditional Chinese Medicine, Chengdu, Sichuan, China. ${ }^{4}$ School of Chinese Medicine, Hong Kong Baptist University, Kowloon, Hong Kong, SAR, China. ${ }^{5}$ Leiden University European Center for Chinese Medicine and Natural Compounds, Institute of Biology, Leiden University, Leiden, The Netherlands.

Received: 14 March 2019 Accepted: 5 June 2019

Published online: 17 June 2019

\section{References}

1. Kaser A, Zeissig S, Blumberg RS. Inflammatory bowel disease. Annu Rev Immunol. 2010;28:573-621.

2. Baumgart DC, Sandborn WJ. Crohn's disease. Lancet. 2012;380:1590-605

3. Ungaro R, Mehandru S, Allen PB, Peyrin-Biroulet L, Colombel JF. Ulcerative colitis. Lancet. 2017;389:1756-70.

4. Ventham NT, Kennedy NA, Nimmo ER, Satsangi J. Beyond gene discovery in inflammatory bowel disease: the emerging role of epigenetics. Gastroenterology. 2013;145:293-308.

5. Lee HS, Park SK, Park DI. Novel treatments for inflammatory bowel disease. Korean J Intern Med. 2018;33:20-7.

6. Sokol H, Seksik P, Cosnes J. Complications and surgery in the inflammatory bowel diseases biological era. Curr Opin Gastroenterol. 2014:30:378-84

7. Hibi T, Imai Y, Murata Y, Matsushima N, Zheng R, Gasink C. Efficacy and safety of ustekinumab in Japanese patients with moderately to severely active Crohn's disease: a subpopulation analysis of phase 3 induction and maintenance studies. Intest Res. 2017;15:475-86.

8. Sandborn WJ, Feagan BG, Wolf DC, D'Haens G, Vermeire S, Hanauer SB, Ghosh S, Smith H, Cravets M, Frohna PA, Aranda R, Gujrathi S, Olson A. Ozanimod induction and maintenance treatment for ulcerative colitis. N Engl J Med. 2016;374:1754-62.

9. Sandborn WJ, Ghosh S, Panes J, Vranic I, Su C, Rousell S, Niezychowski W. Tofacitinib, an oral Janus kinase inhibitor, in active ulcerative colitis. N Engl J Med. 2012;367:616-24.

10. Feagan BG, Rutgeerts P, Sands BE, Hanauer S, Colombel JF, Sandborn WJ, Van Assche G, Axler J, Kim HJ, Danese S, Fox I, Milch C, Sankoh S, Wyant T, Xu J, Parikh A. Vedolizumab as induction and maintenance therapy for ulcerative colitis. N Engl J Med. 2013;369:699-710.

11. Ford AC, Peyrin-Biroulet L. Opportunistic infections with anti-tumor necrosis factor-alpha therapy in inflammatory bowel disease: meta-analysis of randomized controlled trials. Am J Gastroenterol. 2013;108:1268-76.

12. Lin WC, Chou JW, Yen HH, Hsu WH, Lin HH, Lin JK, Chuang CH, Huang TY, Wang HY, Wei SC, Wong JM. Outcomes of limited period of adalimumab treatment in moderate to severe Crohn's disease patients: Taiwan Society of Inflammatory Bowel Disease Study. Intest Res. 2017;15:487-94

13. Ng SC, Lam YT, Tsoi KK, Chan FK, Sung JJ, Wu JC. Systematic review: the efficacy of herbal therapy in inflammatory bowel disease. Aliment Pharmacol Ther. 2013;38:854-63.

14. Langhorst J, Wulfert H, Lauche R, Klose P, Cramer H, Dobos GJ, Korzenik $J$. Systematic review of complementary and alternative medicine treatments in inflammatory bowel diseases. J Crohns Colitis. 2015;9:86-106.

15. Guo BJ, Bian ZX, Qiu HC, Wang YT, Wang Y. Biological and clinical implications of herbal medicine and natural products for the treatment of inflammatory bowel disease. Ann N Y Acad Sci. 2017;1401:37-48.

16. Huang C, Wu X, Wang S, Wang W, Guo F, Chen Y, Pan B, Zhang M, Fan X. Combination of Salvia miltiorrhiza and ligustrazine attenuates bleomycin-induced pulmonary fibrosis in rats via modulating TNFalpha and TGF-beta. Chin Med. 2018;13:36.

17. Zong SY, Pu YQ, Xu BL, Zhang T, Wang B. Study on the physicochemical properties and anti-inflammatory effects of paeonol in rats with TNBSinduced ulcerative colitis. Int Immunopharmacol. 2017:42:32-8.

18. Schicho R, Storr M. Topical and systemic cannabidiol improves trinitrobenzene sulfonic acid colitis in mice. Pharmacology. 2012;89:149-55.

19. Vicentini FA, Barbosa MMC, Fortunato MC, Amado CAB, Comar JF, Longhini R, de Mello JCP, Natali MRM. Treatment with Trichilia catigua ethyl-acetate fraction improves healing and reduces oxidative stress in TNBS-induced colitis in rats. Biomed Pharmacother. 2018;107:194-202.

20. Kang JH, Choi S, Jang JE, Ramalingam P, Ko YT, Kim SY, Oh SH. Wasabia japonica is a potential functional food to prevent colitis via inhibiting the NF-kappaB signaling pathway. Food Funct. 2017:8:2865-74.

21. Prosperi D, Colombo M, Zanoni I, Granucci F. Drug nanocarriers to treat autoimmunity and chronic inflammatory diseases. Semin Immunol. 2017;34:61-7

22. Collnot EM, Ali H, Lehr CM. Nano- and microparticulate drug carriers for targeting of the inflamed intestinal mucosa. J Control Release. 2012;161:235-46

23. Ulbrich W, Lamprecht A. Targeted drug-delivery approaches by nanoparticulate carriers in the therapy of inflammatory diseases. J R Soc Interface. 2010;7(Suppl 1):S55-66.

24. Zhang YZ, Li YY. Inflammatory bowel disease: pathogenesis. World J Gastroenterol. 2014;20:91-9.

25. Khor B, Gardet A, Xavier RJ. Genetics and pathogenesis of inflammatory bowel disease. Nature. 2011:474:307-17.

26. Loddo I, Romano C. Inflammatory bowel disease: genetics, epigenetics, and pathogenesis. Front Immunol. 2015;6:551.

27. Ananthakrishnan AN, Higuchi LM, Huang ES, Khalili H, Richter JM, Fuchs CS, Chan AT. Aspirin, nonsteroidal anti-inflammatory drug use, and risk for Crohn disease and ulcerative colitis: a cohort study. Ann Intern Med. 2012;156:350-9.

28. Shaw SY, Blanchard JF, Bernstein CN. Association between the use of antibiotics in the first year of life and pediatric inflammatory bowel disease. Am J Gastroenterol. 2010;105:2687-92.

29. Camara RJ, Schoepfer AM, Pittet V, Begre S, von Kanel R. Mood and nonmood components of perceived stress and exacerbation of Crohn's disease. Inflamm Bowel Dis. 2011;17:2358-65.

30. Mawdsley JE, Rampton DS. Psychological stress in IBD: new insights into pathogenic and therapeutic implications. Gut. 2005;54:1481-91.

31. Lakatos PL, Szamosi T, Lakatos L. Smoking in inflammatory bowel diseases: good, bad or ugly? World J Gastroenterol. 2007;13:6134-9.

32. Cosnes J. What is the link between the use of tobacco and IBD? Inflamm Bowel Dis. 2008;14(Suppl 2):S14-5.

33. Simpson KW, Dogan B, Rishniw M, Goldstein RE, Klaessig S, McDonough PL, German AJ, Yates RM, Russell DG, Johnson SE, Berg DE, Harel J, Bruant G, McDonough SP, Schukken YH. Adherent and invasive Escherichia coli is associated with granulomatous colitis in boxer dogs. Infect Immun. 2006;74:4778-92.

34. Andoh A, Imaeda H, Aomatsu T, Inatomi O, Bamba S, Sasaki M, Saito Y, Tsujikawa T, Fujiyama Y. Comparison of the fecal microbiota profiles between ulcerative colitis and Crohn's disease using terminal restriction fragment length polymorphism analysis. J Gastroenterol. 2011:46:479-86.

35. Johansson ME, Phillipson M, Petersson J, Velcich A, Holm L, Hansson GC. The inner of the two Muc2 mucin-dependent mucus layers in colon is devoid of bacteria. Proc Natl Acad Sci USA. 2008;105:15064-9.

36. Frank DN, St Amand AL, Feldman RA, Boedeker EC, Harpaz N, Pace NR. Molecular-phylogenetic characterization of microbial community imbalances in human inflammatory bowel diseases. Proc Natl Acad Sci USA. 2007;104:13780-5.

37. Kaser A, Blumberg RS. Autophagy, microbial sensing, endoplasmic reticulum stress, and epithelial function in inflammatory bowel disease. Gastroenterology. 2011;140:1738-47.

38. Salim SY, Soderholm JD. Importance of disrupted intestinal barrier in inflammatory bowel diseases. Inflamm Bowel Dis. 2011;17:362-81.

39. Medzhitov R, Janeway C Jr. Innate immunity. N Engl J Med. 2000:343:338-44 
40. Watanabe T, Kitani A, Murray PJ, Strober W. NOD2 is a negative regulator of Toll-like receptor 2-mediated T helper type 1 responses. Nat Immunol. 2004;5:800-8.

41. Di Sabatino A, Biancheri P, Rovedatti L, MacDonald TT, Corazza GR. New pathogenic paradigms in inflammatory bowel disease. Inflamm Bowel Dis. 2012;18:368-71

42. Ke F, Yadav PK, Ju LZ. Herbal medicine in the treatment of ulcerative colitis. Saudi J Gastroenterol. 2012;18:3-10.

43. Wu X, Wang S, Lu J, Jing Y, Li M, Cao J, Bian B, Hu C. Seeing the unseen of Chinese herbal medicine processing (Paozhi): advances in new perspectives. Chin Med. 2018;13:4

44. Ma X, Hu Y, Li X, Zheng X, Wang Y, Zhang J, Fu C, Geng F. Periplaneta americana ameliorates dextran sulfate sodium-induced ulcerative colitis in rats by Keap1/Nrf-2 activation, intestinal barrier function, and gut microbiota regulation. Front Pharmacol. 2018;9:944.

45. Huang YT, Wen CC, Chen YH, Huang WC, Huang LT, Lin WC, Arulselvan P, Liao JW, Lin SH, Hsiao PW, Kuo SC, Yang NS. Dietary uptake of Wedelia chinensis extract attenuates dextran sulfate sodium-induced colitis in mice. PLOS ONE. 2013;8:e64152.

46. Zhang J, Ding L, Wang B, Ren G, Sun A, Deng C, Wei X, Mani S, Wang Z, Dou W. Notoginsenoside R1 attenuates experimental inflammatory bowel disease via pregnane $X$ receptor activation. J Pharmacol Exp Ther. 2015;352:315-24

47. Zhang X, Wang Y, Ma Z, Liang Q, Tang X, Hu D, Tan H, Xiao C, Gao Y. Tanshinone IIA ameliorates dextran sulfate sodium-induced inflammatory bowel disease via the pregnane $X$ receptor. Drug Des Devel Ther. 2015:9:6343-62.

48. Sandborn WJ, Targan SR, Byers VS, Rutty DA, Mu H, Zhang X, Tang T. Andrographis paniculata extract (HMPL-004) for active ulcerative colitis. Am J Gastroenterol. 2013;108:90-8.

49. Zhang F, Li Y, Xu F, Chu Y, Zhao W. Comparison of Xilei-san, a Chinese herbal medicine, and dexamethasone in mild/moderate ulcerative proctitis: a double-blind randomized clinical trial. J Altern Complement Med. 2013;19:838-42.

50. Hanai H, lida T, Takeuchi K, Watanabe F, Maruyama Y, Andoh A, Tsujikawa T, Fujiyama Y, Mitsuyama K, Sata M, Yamada M, Iwaoka Y, Kanke K, Hiraishi H, Hirayama K, Arai H, Yoshii S, Uchijima M, Nagata T, Koide Y. Curcumin maintenance therapy for ulcerative colitis: randomized, multicenter, double-blind, placebo-controlled trial. Clin Gastroenterol Hepatol. 2006;4:1502-6.

51. Langmead L, Feakins RM, Goldthorpe S, Holt H, Tsironi E, De Silva A, Jewell DP, Rampton DS. Randomized, double-blind, placebo-controlled trial of oral aloe vera gel for active ulcerative colitis. Aliment Pharmacol Ther. 2004;19:739-47.

52. Huber R, Ditfurth AV, Amann F, Guthlin C, Rostock M, Trittler R, Kummerer K, Merfort I. Tormentil for active ulcerative colitis: an openlabel, dose-escalating study. J Clin Gastroenterol. 2007;41:834-8.

53. Ben-Arye E, Goldin E, Wengrower D, Stamper A, Kohn R, Berry E. Wheat grass juice in the treatment of active distal ulcerative colitis: a randomized double-blind placebo-controlled trial. Scand J Gastroenterol. 2002:37:444-9.

54. Liao NS, Ren JA, Fan CG, Wang GF, Zhao YZ, Li JS. Efficacy of polyglycosides of Tripterygium wilfordii in preventing postoperative recurrence of Crohn disease. Zhonghua Wei Chang Wai Ke Za Zhi. 2009:12:167-9.

55. Krebs S, Omer TN, Omer B. Wormwood (Artemisia absinthium) suppresses tumour necrosis factor alpha and accelerates healing in patients with Crohn's disease-a controlled clinical trial. Phytomedicine. 2010;17:305-9.

56. Tang T, Targan SR, Li ZS, Xu C, Byers VS, Sandborn WJ. Randomised clinical trial: herbal extract HMPL-004 in active ulcerative colitis-a double-blind comparison with sustained release mesalazine. Aliment Pharmacol Ther. 2011;33:194-202.

57. Nugent SG, Kumar D, Rampton DS, Evans DF. Intestinal luminal $\mathrm{pH}$ in inflammatory bowel disease: possible determinants and implications for therapy with aminosalicylates and other drugs. Gut. 2001;48:571-7.

58. Thakral S, Thakral NK, Majumdar DK. Eudragit (R): a technology evaluation. Expert Opinion on Drug Delivery. 2013;10:131-49.

59. Kim BR, Seo HS, Ku JM, Kim GJ, Jeon CY, Park JH, Jang BH, Park SJ, Shin YC, Ko SG. Silibinin inhibits the production of pro-inflammatory cytokines through inhibition of NF-kappaB signaling pathway in HMC-1 human mast cells. Inflamm Res. 2013;62:941-50.

60. Varshosaz J, Minaiyan M, Khaleghi N. Eudragit nanoparticles loaded with silybin: a detailed study of preparation, freeze-drying condition and in vitro/in vivo evaluation. J Microencapsul. 2015;32:211-23.

61. Kocaadam B, Sanlier N. Curcumin, an active component of turmeric (Curcuma longa), and its effects on health. Crit Rev Food Sci Nutr. 2017;57:2889-95

62. Wang SP, Tan M, Zhong ZF, Chen MW, Wang YT. Nanotechnologies for curcumin: an ancient puzzler meets modern solutions. J Nanomater. 2011. https://doi.org/10.1155/2011/723178.

63. Niedzwiecki A, Roomi MW, Kalinovsky T, Rath M. Anticancer efficacy of polyphenols and their combinations. Nutrients. 2016;8:E552.

64. Zhong WH, Qian KJ, Xiong JB, Ma K, Wang AZ, Zou Y. Curcumin alleviates lipopolysaccharide induced sepsis and liver failure by suppression of oxidative stress-related inflammation via PI3K/AKT and NF-kappa B related signaling. Biomed Pharmacother. 2016;83:302-13.

65. Lewis JD, Abreu MT. Diet as a trigger or therapy for inflammatory bowel diseases. Gastroenterology. 2017;152:398.

66. Beloqui A, Coco R, Memvanga PB, Ucakar B, de Rieux A, Preat V. pHsensitive nanoparticles for colonic delivery of curcumin in inflammatory bowel disease. Int J Pharm. 2014;473:203-12.

67. Blanco-Garcia E, Otero-Espinar FJ, Blanco-Mendez J, Leiro-Vidal JM, Luzardo-Alvarez A. Development and characterization of anti-inflammatory activity of curcumin-loaded biodegradable microspheres with potential use in intestinal inflammatory disorders. Int J Pharm. 2017:518:86-104.

68. Xiao B, Si X, Zhang M, Merlin D. Oral administration of pH-sensitive curcumin-loaded microparticles for ulcerative colitis therapy. Colloids Surf B Biointerfaces. 2015;135:379-85.

69. Sareen R, Nath K, Jain N, Dhar KL. Curcumin loaded microsponges for colon targeting in inflammatory bowel disease: fabrication, optimization, and in vitro and pharmacodynamic evaluation. Biomed Res Int. 2014;2014:340701.

70. Abdel Ghaffar AM, Radwan RR, Ali HE. Radiation synthesis of poly(starch/acrylic acid) $\mathrm{pH}$ sensitive hydrogel for rutin controlled release. Int J Biol Macromol. 2016;92:957-64.

71. Jeong YI, Prasad Yv R, Ohno T, Yoshikawa Y, Shibata N, Kato S, Takeuchi K, Takada K. Application of Eudragit P-4135F for the delivery of ellagic acid to the rat lower small intestine. J Pharm Pharmacol. 2001;53:1079-85.

72. Dong K, Zeng AG, Wang ML, Dong YL, Wang K, Guo CN, Yan Y, Zhang $\mathrm{L}$, Shi XP, Xing JF. In vitro and in vivo study of a colon-targeting resin microcapsule loading a novel prodrug, 3,4,5-tributyryl shikimic acid. Rsc Adv. 2016;6:16882-90.

73. Yum S, Jeong S, Lee S, Nam J, Kim W, Yoo JW, Kim MS, Lee BL, Jung Y. Colon-targeted delivery of piceatannol enhances anti-colitic effects of the natural product: potential molecular mechanisms for therapeutic enhancement. Drug Des Devel Ther. 2015;9:4247-58.

74. Davis SS, Hardy JG, Fara JW. Transit of pharmaceutical dosage forms through the small intestine. Gut. 1986;27:886-92.

75. Liu DW, Yan HJ, Kong YM, You Y, Li YL, Wang LX, Tong Y, Wang JY. Preparation of colon-targeted acetylharpagide tablets and its release properties in vivo and in vitro. Front Pharmacol. 2018:9:832

76. Bassotti G, Gaburri M. Manometric investigation of high-amplitude propagated contractile activity of the human colon. Am J Physiol. 1988;255:G660-4

77. Basit AW, Short MD, McConnell EL. Microbiota-triggered colonic delivery: robustness of the polysaccharide approach in the fed state in man. J Drug Target. 2009;17:64-71.

78. Chourasia MK, Jain SK. Polysaccharides for colon targeted drug delivery. Drug Deliv. 2004;11:129-48.

79. Pinto JF. Site-specific drug delivery systems within the gastro-intestinal tract: from the mouth to the colon. Int J Pharm. 2010;395:44-52.

80. Rabiskova M, Bautzova T, Gajdziok J, Dvorackova K, Lamprecht A, Pellequer Y, Spilkova J. Coated chitosan pellets containing rutin intended for the treatment of inflammatory bowel disease: in vitro characteristics and in vivo evaluation. Int J Pharm. 2012;422:151-9.

81. Marques FZ, Markus MA, Morris BJ. Resveratrol: cellular actions of a potent natural chemical that confers a diversity of health benefits. Int J Biochem Cell Biol. 2009:41:2125-8. 
82. Wang S, Chen R, Morott J, Repka MA, Wang Y, Chen M. mPEG-b-PCL/ TPGS mixed micelles for delivery of resveratrol in overcoming resistant breast cancer. Expert Opin Drug Deliv. 2015;12:361-73.

83. Abdin AA. Targeting sphingosine kinase 1 (SphK1) and apoptosis by colon-specific delivery formula of resveratrol in treatment of experimental ulcerative colitis in rats. Eur J Pharmacol. 2013;718:145-53.

84. Indran IR, Liang RL, Min TE, Yong EL. Preclinical studies and clinical evaluation of compounds from the genus Epimedium for osteoporosis and bone health. Pharmacol Ther. 2016;162:188-205.

85. Wang QS, Wang GF, Zhou J, Gao LN, Cui YL. Colon targeted oral drug delivery system based on alginate-chitosan microspheres loaded with icariin in the treatment of ulcerative colitis. Int J Pharm. 2016:515:176-85.

86. Castangia I, Nacher A, Caddeo C, Merino V, Diez-Sales O, Catalan-Latorre A, Fernandez-Busquets X, Fadda AM, Manconi M. Therapeutic efficacy of quercetin enzyme-responsive nanovesicles for the treatment of experimental colitis in rats. Acta Biomater. 2015;13:216-27.

87. Qiao H, Fang D, Chen J, Sun Y, Kang C, Di L, Li J, Chen Z, Chen J, Gao Y. Orally delivered polycurcumin responsive to bacterial reduction for targeted therapy of inflammatory bowel disease. Drug Deliv. 2017;24:233-42

88. Mutalik S, Suthar NA, Managuli RS, Shetty PK, Avadhani K, Kalthur G, Kulkarni RV, Thomas R. Development and performance evaluation of novel nanoparticles of a grafted copolymer loaded with curcumin. Int J Biol Macromol. 2016;86:709-20.

89. Tang J, Raza A, Chen J, Xu HX. A systematic review on the sinomenine derivatives. Mini Rev Med Chem. 2018;18:906-17.

90. Xiong HF, Tian L, Zhao ZH, Chen SP, Zhao QY, Hong JB, Xie Y, Zhou NJ, Fu $Y J$. The sinomenine enteric-coated microspheres suppressed the TLR/ NF-kappa B signaling in DSS-induced experimental colitis. Int Immunopharmacol. 2017:50:251-62.

91. Mongia RP, Rakesh R, Ankur K, et al. Biodistribution and targeting potential assessment of mucoadhesive chitosan nanoparticles designed for ulcerative colitis via scintigraphy. RSC Adv. 2018;8(37):20809-21.

92. Xiao B, Zhang Z, Viennois E, Kang Y, Zhang M, Han MK, Chen J, Merlin D. Combination therapy for ulcerative colitis: orally targeted nanoparticles prevent mucosal damage and relieve inflammation. Theranostics. 2016:6:2250-66.

93. Li Q, Zhai W, Jiang Q, Huang R, Liu L, Dai J, Gong W, Du S, Wu Q. Curcumin-piperine mixtures in self-microemulsifying drug delivery system for ulcerative colitis therapy. Int J Pharm. 2015;490:22-31.

94. Duan H, Lu S, Gao C, Bai X, Qin H, Wei Y, Wu X, Liu M. Mucoadhesive microparticulates based on polysaccharide for target dual drug delivery of 5-aminosalicylic acid and curcumin to inflamed colon. Colloids Surf B Biointerfaces. 2016;145:510-9.

95. Gugulothu D, Kulkarni A, Patravale V, Dandekar P. pH-sensitive nanoparticles of curcumin-celecoxib combination: evaluating drug synergy in ulcerative colitis model. J Pharm Sci. 2014;103:687-96.

96. Khan N, Mukhtar H. Tea polyphenols for health promotion. Life Sci. 2007;81:519-33.

97. Wang SP, Zhang JM, Chen MW, Wang YT. Delivering flavonoids into solid tumors using nanotechnologies. Expert Opin Drug Deliv. 2013:10:1411-28.

98. Wang S, Chen R, Zhong Z, Shi Z, Chen M, Wang Y. Epigallocatechin3-gallate potentiates the effect of curcumin in inducing growth inhibition and apoptosis of resistant breast cancer cells. Am J Chin Med. 2014:42:1279-300

99. Bitzer ZT, Elias RJ, Vijay-Kumar M, Lambert JD. (-)-Epigallocatechin3-gallate decreases colonic inflammation and permeability in a mouse model of colitis, but reduces macronutrient digestion and exacerbates weight loss. Mol Nutr Food Res. 2016;60:2267-74

100. Oz HS, Chen T, de Villiers WJ. Green tea polyphenols and sulfasalazine have parallel anti-inflammatory properties in colitis models. Front Immunol. 2013:4:132.

101. Gou SQ, Chen QB, Liu Y, Zeng L, Song HL, Xu ZG, Kang YJ, Li CM, Xiao B. Green fabrication of ovalbumin nanoparticles as natural polyphenol carriers for ulcerative colitis therapy. Acs Sustain Chem Eng. 2018;6:12658-67.

102. Lozano-Perez AA, Rodriguez-Nogales A, Ortiz-Cullera V, Algieri F, Garrido-Mesa J, Zorrilla P, Rodriguez-Cabezas ME, Garrido-Mesa N, Utrilla MP, De Matteis L, de la Fuente JM, Cenis JL, Galvez J. Silk fibroin nanoparticles constitute a vector for controlled release of resveratrol in an experimental model of inflammatory bowel disease in rats. Int J Nanomed. 2014:9:4507-20.

103. Souza MP, Vaz AFM, Correia MTS, Cerqueira MA, Vicente AA, Carneiroda-Cunha MG. Quercetin-loaded lecithin/chitosan nanoparticles for functional food applications. Food Bioprocess Technol. 2014;7:1149-59.

104. Lozano-Perez AA, Rivero HC, Perez Hernandez MDC, Pagan A, Montalban MG, Villora G, Cenis JL. Silk fibroin nanoparticles: efficient vehicles for the natural antioxidant quercetin. Int J Pharm. 2017;518:11-9.

105. Tan W, Li Y, Chen M, Wang Y. Berberine hydrochloride: anticancer activity and nanoparticulate delivery system. Int J Nanomed. 2011;6:1773-7.

106. Pund S, Borade G, Rasve G. Improvement of anti-inflammatory and antiangiogenic activity of berberine by novel rapid dissolving nanoemulsifying technique. Phytomedicine. 2014;21:307-14

107. Huang YF, Zhou JT, Qu C, Dou YX, Huang QH, Lin ZX, Xian YF, Xie JH, Xie YL, Lai XP, Su ZR. Anti-inflammatory effects of Brucea javanica oil emulsion by suppressing NF-kappaB activation on dextran sulfate sodiuminduced ulcerative colitis in mice. J Ethnopharmacol. 2017;198:389-98.

108. Dou YX, Zhou JT, Wang TT, Huang YF, Chen VP, Xie YL, Lin ZX, Gao JS, Su ZR, Zeng HF. Self-nanoemulsifying drug delivery system of bruceine D: a new approach for anti-ulcerative colitis. Int J Nanomed. 2018;13:5887-907.

109. Liu W, Guo W, Guo L, Gu Y, Cai P, Xie N, Yang X, Shu Y, Wu X, Sun Y, Xu Q. Andrographolide sulfonate ameliorates experimental colitis in mice by inhibiting Th1/Th17 response. Int Immunopharmacol. 2014;20:337-45.

110. Ye L, Wang T, Tang L, Liu W, Yang Z, Zhou J, Zheng Z, Cai Z, Hu M, Liu Z. Poor oral bioavailability of a promising anticancer agent andrographolide is due to extensive metabolism and efflux by P-glycoprotein. J Pharm Sci. 2011;100:5007-17.

111. Yen CC, Chen YC, Wu MT, Wang CC, Wu YT. Nanoemulsion as a strategy for improving the oral bioavailability and anti-inflammatory activity of andrographolide. Int J Nanomed. 2018;13:669-80.

112. Schaible AM, Traber $H$, TemmI V, Noha SM, Filosa R, Peduto A, Weinige C, Barz D, Schuster D, Werz O. Potent inhibition of human 5-lipoxygenase and microsomal prostaglandin $\mathrm{E}(2)$ synthase-1 by the anti-carcinogenic and anti-inflammatory agent embelin. Biochem Pharmacol. 2013;86:476-86

113. Badamaranahalli SS, Kopparam M, Bhagawati ST, Durg S. Embelin lipid nanospheres for enhanced treatment of ulcerative colitis-preparation, characterization and in vivo evaluation. Eur J Pharm Sci. 2015;76:73-82.

114. Oidtmann J, Schantz M, Mader K, Baum M, Berg S, Betz M, Kulozik U, Leick S, Rehage H, Schwarz K, Richling E. Preparation and comparative release characteristics of three anthocyanin encapsulation systems. J Agric Food Chem. 2012;60:844-51.

115. Beloqui A, Memvanga PB, Coco R, Reimondez-Troitino S, Alhouayek M, Muccioli GG, Alonso MJ, Csaba N, de la Fuente M, Preat V. A comparative study of curcumin-loaded lipid-based nanocarriers in the treatment of inflammatory bowel disease. Colloids Surf B Biointerfaces. 2016;143:327-35

116. Yadav VR, Suresh S, Devi K, Yadav S. Novel formulation of solid lipid microparticles of curcumin for anti-angiogenic and anti-inflammatory activity for optimization of therapy of inflammatory bowel disease. J Pharm Pharmacol. 2009:61:311-21.

117. Nikkhah Bodagh M, Maleki I, Hekmatdoost A. Ginger in gastrointestinal disorders: a systematic review of clinical trials. Food Sci Nutr. 2019;7:96-108.

118. Langner E, Greifenberg S, Gruenwald O. Ginger: history and use. Adv Ther. 1998;15:25-44.

119. Zhang M, Viennois E, Prasad M, Zhang Y, Wang L, Zhang Z, Han MK, Xiao B, Xu C, Srinivasan S, Merlin D. Edible ginger-derived nanoparticles: a novel therapeutic approach for the prevention and treatment of inflammatory bowel disease and colitis-associated cancer. Biomaterials. 2016;101:321-40.

120. Zhang M, Wang X, Han MK, Collins JF, Merlin D. Oral administration of ginger-derived nanolipids loaded with siRNA as a novel approach for efficient siRNA drug delivery to treat ulcerative colitis. Nanomedicine (Lond). 2017;12:1927-43.

121. Zhang M, Xu C, Liu D, Han MK, Wang L, Merlin D. Oral delivery of nanoparticles loaded with ginger active compound, 6-shogaol, attenuates ulcerative colitis and promotes wound healing in a murine model of ulcerative colitis. J Crohns Colitis. 2018:12:217-29. 
122. Ju S, Mu J, Dokland T, Zhuang X, Wang Q, Jiang H, Xiang X, Deng ZB, Wang B, Zhang L, Roth M, Welti R, Mobley J, Jun Y, Miller D, Zhang HG. Grape exosome-like nanoparticles induce intestinal stem cells and protect mice from DSS-induced colitis. Mol Ther. 2013;21:1345-57.

123. Teng Y, Ren Y, Sayed M, Hu X, Lei C, Kumar A, Hutchins E, Mu J, Deng Z, Luo C, Sundaram K, Sriwastva MK, Zhang L, Hsieh M, Reiman R, Haribabu B, Yan J, Jala VR, Miller DM, Van Keuren-Jensen K, Merchant ML, McClain CJ, Park JW, Egilmez NK, Zhang HG. Plant-derived exosomal microRNAs shape the gut microbiota. Cell Host Microbe. 2018;24(637-652):e8.

124. Li Q, Niu Y, Xing P, Wang C. Bioactive polysaccharides from natural resources including Chinese medicinal herbs on tissue repair. Chin Med. 2018;13:7.

125. Jin ML, Zhao K, Huang QS, Xu CL, Shang P. Isolation, structure and bioactivities of the polysaccharides from Angelica sinensis (Oliv.) diels: a review. Carbohyd Polym. 2012;89:713-22.

126. Zhou S, Zhang B, Liu X, Teng Z, Huan M, Yang T, Yang Z, Jia M, Mei Q. A new natural angelica polysaccharide based colon-specific drug delivery system. J Pharm Sci. 2009;98:4756-68.

127. Thakur VK, Thakur MK. Recent trends in hydrogels based on psyllium polysaccharide: a review. J Cleaner Prod. 2014;82:1-15.

128. Singh B. Psyllium as therapeutic and drug delivery agent. Int J Pharm. 2007;334:1-14.

129. Leenen $\mathrm{CH}$, Dieleman LA. Inulin and oligofructose in chronic inflammatory bowel disease. J Nutr. 2007;137:2572S-5S.

130. Shivhare K, Garg C, Priyam A, Gupta A, Sharma AK, Kumar P. Enzyme sensitive smart inulin-dehydropeptide conjugate self-assembles into nanostructures useful for targeted delivery of ornidazole. Int J Biol Macromol. 2018;106:775-83.
131. Sun Q, Luan L, Arif M, Li J, Dong QJ, Gao Y, Chi Z, Liu CG. Redox-sensitive nanoparticles based on 4-aminothiophenol-carboxymethyl inulin conjugate for budesonide delivery in inflammatory bowel diseases. Carbohydr Polym. 2018;189:352-9.

132. Yang F, Fang XY, Jiang WT, Chen TF. Bioresponsive cancer-targeted polysaccharide nanosystem to inhibit angiogenesis. Int J Nanomed. 2017;12:7419-31.

133. Zhu C, Zhang S, Song C, Zhang Y, Ling Q, Hoffmann PR, Li J, Chen T, Zheng W, Huang Z. Selenium nanoparticles decorated with Ulva lactuca polysaccharide potentially attenuate colitis by inhibiting NF-kappaB mediated hyper inflammation. J Nanobiotechnol. 2017;15:20.

134. Yin H, Fang J, Liao L, Nakamura H, Maeda H. Styrene-maleic acid copolymer-encapsulated CORM2, a water-soluble carbon monoxide (CO) donor with a constant CO-releasing property, exhibits therapeutic potential for inflammatory bowel disease. J Control Release. 2014;187:14-21.

135. Park J, Pramanick S, Park D, Yeo J, Lee J, Lee H, Kim WJ. Therapeutic-gasresponsive hydrogel. Adv Mater. 2017;29:44

136. Lin WC, Pan WY, Liu CK, Huang WX, Song HL, Chang KS, Li MJ, Sung HW. In situ self-spray coating system that can uniformly disperse a poorly water-soluble $\mathrm{H}_{2} \mathrm{~S}$ donor on the colorectal surface to treat inflammatory bowel diseases. Biomaterials. 2018;182:289-98.

\section{Publisher's Note}

Springer Nature remains neutral with regard to jurisdictional claims in published maps and institutional affiliations.
Ready to submit your research? Choose BMC and benefit from:

- fast, convenient online submission

- thorough peer review by experienced researchers in your field

- rapid publication on acceptance

- support for research data, including large and complex data types

- gold Open Access which fosters wider collaboration and increased citations

- maximum visibility for your research: over 100M website views per year

At BMC, research is always in progress.

Learn more biomedcentral.com/submissions 